\title{
Unconventional Applications of Aerospace Engineering: Effects of a Design Elective on Perception of Aerospace
}

\section{Ms. Hannah Rose Stroud, Texas A\&M University}

Hannah Stroud is a first year masters student at Texas A\&M University. Her research interests include unconventional applications of aerospace technology with an emphasis on smart materials and structural optimization. She is co-advised by Dr. Kristi Shryock and Dr. Darren Hartl.

\section{Dr. Kristi J. Shryock, Texas A\&M University}

Dr. Kristi J. Shryock is the Frank and Jean Raymond Foundation Inc. Endowed Instructional Associate Professor and Associate Department Head in the Department of Aerospace Engineering in the College of Engineering at Texas A\&M University. She also serves as Director of the Craig and Galen Brown Engineering Honors Program. She received her BS, MS, and PhD from the College of Engineering at Texas A\&M. Kristi works to improve the undergraduate engineering experience through evaluating preparation in areas, such as mathematics and physics, evaluating engineering identity and its impact on retention, incorporating non-traditional teaching methods into the classroom, and engaging her students with interactive methods.

\section{Dr. Darren John Hartl, Texas A\&M University}

Darren J. Hartl received his BS in Aerospace Engineering in 2004 and Ph.D. in Aerospace Engineering in 2009, both from Texas A\&M University. He currently holds an Assistant Professor position at Texas A\&M in his home department, and his work bridges the topics of advanced multifunctional material systems and their integration into aerospace platforms. After over three years as a Research Assistant Professor at Texas A\&M, Dr. Hartl accepted joint appointments working at the Air Force Research Laboratory (AFRL) in the Materials and Manufacturing Directorate and Aerospace Systems Directorate. At Texas A\&M, Dr. Hartl maintains a large and active research team consisting of graduate, undergraduate, and postdoctoral researchers. Darren has over 17 years of experience working with shape memory alloys and morphing structures and his efforts have included both experimental and theoretical studies. Since 2006, Darren has co-authored 158 technical publications on the topics of active materials modeling, testing, and integration into morphing structures. He has given over 25 invited talks or seminars (10 international) and has taught short courses on SMA theories in the US, Europe, and Asia. Since 2014, he has served as an Associate Editor for the Journal of Intelligent Material Systems and Structures. He was recently selected as the 2016 recipient of the ASME Gary Anderson Early Achievement Award for his contributions to the smart materials and adaptive structures communities.

\section{Dr. Isaac Emmanuel Sabat, Texas A\&M University}

Isaac Sabat's program of research broadly focuses on understanding and improving the working lives of stigmatized employees. He is particularly interested in examining strategies in which these employees can engage, such as disclosing or acknowledging their identities, to effectively remediate the workplace obstacles that they face. He has conducted various interrelated projects that examine how the effectiveness of expressing one's identity is impacted by the extent to which stigmas are previously known, visible, or discovered by others over time. This is a novel area, given that disclosures have previously been conceptualized as a dichotomous, all-or-nothing phenomenon. This work has been published in Journal of Business and Psychology, Journal of Organizational Behavior, Journal of Vocational Behavior, and Harvard Business Review.

\section{Ms. Kelly K. Dray, Texas A\&M University}

Kelly K. Dray is a Ph.D. student in Industrial/Organizational Psychology at Texas A\&M University. Her research interests include (1) how various stigmatized identities relate to occupational health outcomes and (2) best conflict management and confrontation techniques to use within organizations. 


\title{
Unconventional Applications of Aerospace Engineering: Effects of a Design Elective on Perception of Aerospace
}

\begin{abstract}
Increasing the number and diversity of science, technology, engineering, and mathematics (STEM) graduates is important to our country's continued economic growth and is an area of national interest as this need continues to rise. In addition to the number of STEM graduates is the need for graduates to work effectively on teams. Diversity within engineering groups has been shown to positively impact a team's body of knowledge on a given topic, as well as improve that group's creativity, ethical decision-making, and ability to function as a cohesive unit. Aerospace engineering is unique in that traditional methods of attracting more students from diverse backgrounds have been less effective than in other STEM fields, and average percentages for minority groups in aerospace are historically lower than other engineering groups. Often times, prospective students attribute their disinterest in aerospace to a narrow focus of the field or limited job opportunities. The National Science Foundation Revolutionizing Engineering Departments (NSF RED) project at Texas A\&M University seeks to expand diversity and inclusion within the aerospace engineering department through increasing visibility of non-traditional applications of fundamental aerospace concepts. As part of this effort, a new senior-level design elective, AERO 489: Unconventional Applications for Aerospace Skills, has been introduced. In this course, students explore non-traditional design spaces (i.e., areas that are not perceived as typically aerospace, and how fundamental structures, fluids, and dynamics apply in these areas). The goal of the class is to encourage students to draw correlations between their field and fields they previously viewed as unrelated to aerospace. One major component of this class is the final project for which students must apply knowledge and software taught in previous aerospace courses to nontraditional applications. For instance, students in the current class have utilized aerospace fundamentals to design and model a directed flow inhaler, a smart tourniquet, and a stent deployment system. All three projects were selected based on their relevance to fluids, structures, and dynamics, as well as their distinct separation from traditional aerospace problems. The paper will discuss results from the semester-long course including student feedback, ability of the students to apply their fundamental knowledge to areas outside of the traditional aerospace domain, and the ability of students to use this knowledge in their career choice selection.
\end{abstract}




\section{Introduction}

The aerospace engineering department at Texas A\&M University focuses primarily on traditional applications of aerospace engineering: airplanes and spacecraft. While research in aerospace engineering has become more diverse in recent years, applications beyond spacecraft and airplanes have not filtered into the curriculum. As a result, students see available careers limited to these traditional areas, including military technology and space exploration. This is a problem faced by many aerospace departments and is likely a reason why there is a lack of diversity among the types of students attracted to this area.

Despite the current focus on airplanes and spacecraft in undergraduate courses, fundamental aerospace engineering concepts have a wide variety of applications. Recent applications of aerospace engineering include flying commuters (e.g., personal air commute; flying cars), data handling (e.g., integrating surveillance from vehicles and aircraft), craft to craft communication (e.g., how vehicles/robots communicate with each other), and health-care (e.g., using simulations to learn how to better care for patients). These alternate applications of the field may speak to and attract a more diverse set of students. Students with different gender identities, ethnicities, ages, religions, nationalities, backgrounds, and beliefs may be more interested in these alternate applications of the field. For example, women have been shown to gravitate towards stereotypically feminine fields, such as arts and humanities [1], and prior research has shown how incorporating more communal applications of STEM fields can improve gender-representation [2]. Furthermore, individuals from minority religions, nationalities, and belief-systems may be less likely to pursue fields that are perceived to be primarily focused on serving the U.S. military, and without a visible alternative the many defense applications aerospace touts may be a major detractor.

The importance of increasing the number and diversity of graduates with bachelor's degrees in STEM has been highlighted in several national reports [3, 4]. To answer calls, such as the 2012 President's Council on Science and Technology stated need for 1 million more STEM degrees in the next decade, the 2011 President's Council on Jobs and Competitiveness goal of 10,000 more engineering students from US colleges and universities each year, and the Texas Workforce Commission estimated state projected need of 62,000 more engineers ( $25 \%$ increase) by 2022 , developing strategic pathways to increase achievement of STEM degrees for all students, in particular for underrepresented populations, is essential [5, 6, 7]. Texas is a key contributor to the overall increase in the number of STEM graduates and increasing underrepresented populations earning a STEM degree for two reasons: (a) State will experience the largest headcount growth of high school graduates in the next ten years; over 87,000 more graduates by 2025 [8] and (b) in 2011, US Census Bureau[9] reported Texas was one of five majority minority states. While the AERO program traditionally has over $90 \%$ of the undergraduate students entering from high schools in Texas, the current ethnic and gender diversity of the student population does not reflect the ethnic makeup of the state.

A recent initiative by Texas A\&M University seeks to diversify the aerospace department organically through an "aerospace skills" based approach to design in an effort to overcome the narrow reputation the discipline often has. The authors sought to take the first steps in answering the proposed question, "How can the introduction and use of non-traditional applications of 
aerospace affect diversity?" This research is in the early stages of a multi-year study, and therefore only the initial phases are within the scope of this paper. Although we eventually seek to establish long-term, causal effects of these curricular changes, the current study presents a first approach in demonstrating the utility of this strategy in improving diversity and inclusion within aerospace programs. Specifically, this paper tests our research question by examining the perceptual outcomes associated with our implementation of a non-traditional senior design elective.

This work intends to focus solely on the introduction of non-traditional concepts rather than introduction of aerospace fundamentals; as a result, implementation of this class at the senior level is imperative. Senior level students already possess fundamental aerospace skills through their previous classwork. Therefore, not only can this class focus on non-traditional applications without having to instruct students on fundamentals for the first time, but students' opinions of the class are not dependent on whether they personally enjoyed the particular aerospace subject and can instead be based on the novel applications introduced. In addition, implementation at the senior level appropriately builds a foundation for future work in two areas: a senior capstone design option as well as in-class labs and activities at a sophomore and junior level. Senior capstone design is one of the most highlighted features to prospective students, and therefore these two future projects will have sufficient exposure to test the authors' hypothesis that introduction of non-traditional aerospace applications will ultimately improve recruitment and retention, and therefore diversity.

\section{Research Approach}

The goal of this study is to determine whether introducing non-traditional aerospace applications to students affects those students' perceptions of aerospace engineering. Initially, student perceptions of the field of aerospace engineering were assessed with a pre-class survey. Towards the end of the class, students were interviewed to assess their experiences within the class itself. After the course was completed, students were given a post-test survey to assess changes in perceptions of the field of aerospace engineering resulting from the class.

\subsection{Class Demographics and Background}

This class attracted a more diverse range of students than represented by the undergraduate-level aerospace department as a whole. Of the 14 students who completed the course, $21 \%$ were female, on par with the 2018 numbers for the aerospace department. However, $66 \%$ of the class comprised of underrepresented racial minorities, compared to the department mean of $36 \%$. All of the women in the class were from underrepresented racial minority groups. Visual comparison is shown below. 


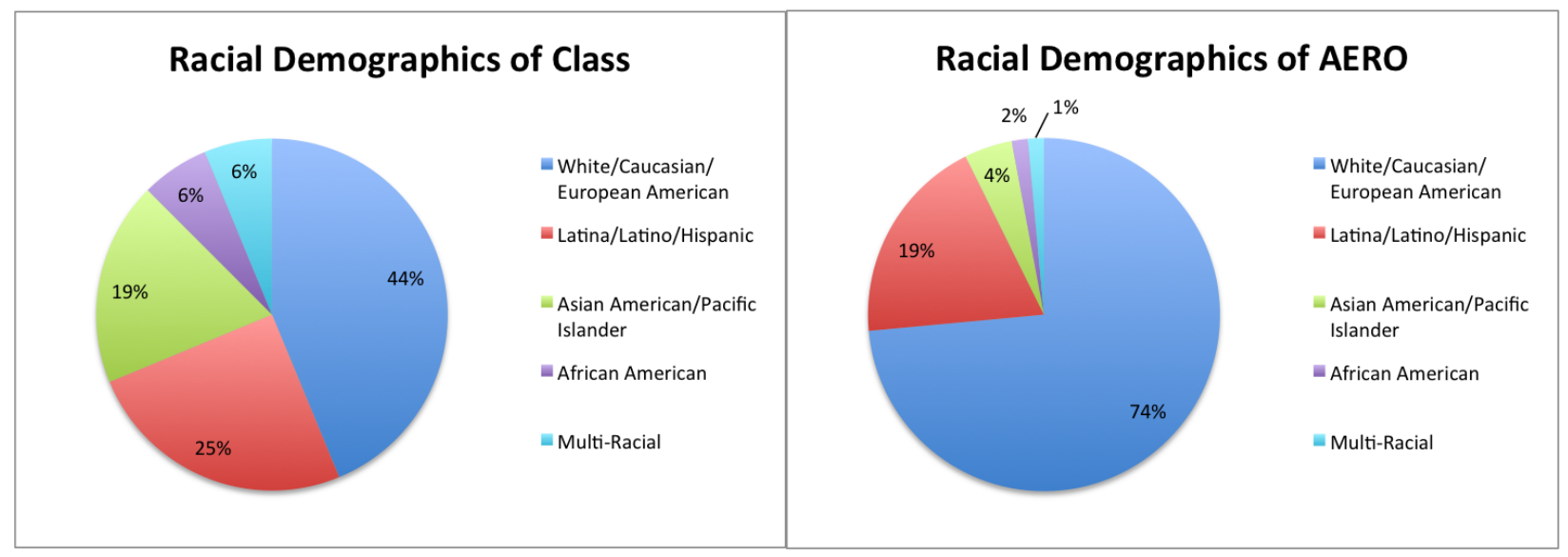

(a) Racial demographics of design elective.

(b) Racial demographics of aerospace department.

Figure 1: Racial demographics of class compared with department as a whole.

\subsection{Class Structure and Implementation}

The format of the class is designed to encourage students to view their aerospace knowledge from a skills-based perspective rather than from an application-based perspective. The class itself is designed to present students with challenges that play to their engineering strengths- in particular, the aerospace fundamentals of fluids, structures, and dynamics and controls- outside of standard examples presented in their typical class environment.

The class is composed of four primary components: in-class/homework activities that introduce and expand upon intended concepts, lectures that bridge the gaps between typical aerospace study and some more technical areas of engineering, guest lectures from individuals in non-aerospace fields but who have aerospace backgrounds, and a major project where students must use their aerospace skills to solve an unconventional problem.

Figure 2 depicts a visual interpretation of the projects developed in this course. The goal of this class is to identify and explore areas where aerospace students' knowledge is high, but perceived relation to aerospace is low- that is, explore areas that are heavy in fluids, structures, and dynamics that do not explicitly resemble an aerospace vehicle. Some examples of early project ideas are plotted on this matrix to demonstrate their approximate relations between these two areas. As the class matures, projects will converge toward the blue region, where the focus will be on a few aerospace fundamentals while trending away from looking like a conventional aerospace problem; this will eventually allow for a diverse range of student-motivated project options. In this first iteration, however, projects are chosen by the instructors to be as soundly in the green area as possible, meaning they have a very strong relationship to fluids, structures, and dynamics, but appear very different from traditional aerospace problems. 


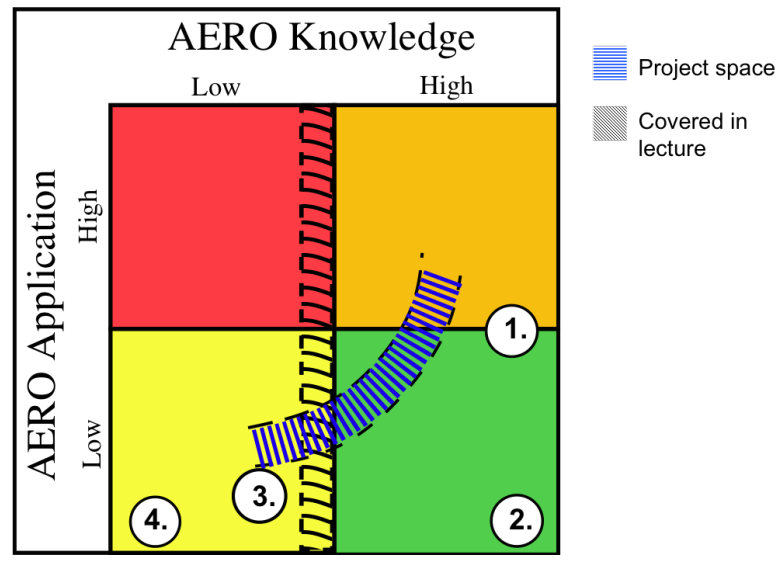

Figure 2: Matrix of aerospace knowledge vs. "standard" aerospace applications. Some preliminary project ideas are shown: 1. Rural medicine delivery via payload drop. 2. Directed flow inhalers. 3. Controllable catheter. 4. Intelligent hemostasis.

\subsubsection{Activities and Guest Lectures}

The activities introduced during the course are formatted in such a way that students develop the ability to draw aerospace connections to increasingly non-obviously related problems.

The first set of activities includes fairly related engineering issues, such as wind turbines and airflow over a causeway. The causeway activity uses a real world example of the intersection of aerospace and civil engineering where pelicans are becoming trapped on a busy causeway due to downdrafts resulting from the cement barrier. Students must use their combined aerodynamics and structures knowledge to design a solution that still prevents cars from driving off the road while also protecting the pelicans from the downdraft. In the wind turbine activity, students are asked to develop by hand a structural model of the turbine tower under certain wind conditions. A lecture introduces the students to the relationship between turbine power output and wind speed, allowing students to then develop a model for wind turbine performance and blade speeds in a given area of the country with certain average wind conditions. This example is further developed from a structural design aspect, and students are exposed to engineering design and optimization techniques using this wind turbine. Students are first asked to do a simple optimization using their hand calculations and the Excel Solver tool. They then develop a design of experiment to determine which design factors affect the results the most. Finally, students are tasked with writing their own optimization algorithm to determine the best design for this turbine.

The next set of activities is further from traditional aerospace and venture into biomedical and petroleum engineering. In the biomedical activity, students must develop a kinematic model of the motion of a mandible using the concepts they learned in their earlier dynamics classes. At this point in the course, the students have developed some familiarity with unconventional aerospace problems. Therefore, for their work in petroleum, the students are asked to independently explore engineering problems the oil and gas industry faces that require knowledge of aerospace engineering, especially focusing on the problems that combine aerodynamics, structures, and dynamic systems. The students then present their findings. 
Students are also exposed to aerospace concepts employed outside of the field in real world scenarios via guest lectures. An oral and maxillofacial surgeon presented the first guest lecture. His work largely focused on facial reconstruction after a traumatic injury, and the need to produce lighter structural elements to replace damaged bone along with the dynamics involved in some robotic-assisted procedures led to a collaboration with aerospace engineers. Students saw first-hand how their knowledge of these two areas could apply to the surgical field as well as before and after examples of the impact this type of work could have. A practicing petroleum engineer whose educational background is in aerospace gave the second guest lecture. This talk highlighted the transition between education and application, and the relationship between aerospace fluids, structures, and offshore rigs was discussed and explored. Students easily related to the speaker's educational background, and therefore could better relate their own skill set to this work.

\subsubsection{Major Project Descriptions and Design Solutions}

Next, the major project is introduced, and students are provided with additional lectures to aid them in their design process. Because the class is in its first iteration, the project options are all selected to be in one field: the biomedical field. Therefore, lectures do not only focus on design methods, but on bridging the gap between aerospace and biomedical as well. In this course version, the additional lectures consist of systems engineering approaches to design, the Situation-Problem-Implication-Need (SPIN) approach to concept pitching to provide students with experience "selling" their ideas, single and multi-objective optimization, forward-coupled modeling, and engineering assumptions for cardiovascular mechanics modeling. Additional resources, including industry experts in each of the project areas, are made available to the students as well.

Three project options are provided for students to choose from. Students could choose to design a configurable inhaler capable of targeting medicine deposition to a single lung, the deployment process of a stent as it is inserted into an artery, or a tourniquet as it tightens to occlude blood flow. Each of these projects requires a structural and a fluid model. All teams used Abaqus FEA, a finite element analysis tool, to develop their structural model. Fluid models varied between teams from commercial computational fluid dynamics (CFD) tools to sequences of mathematical expressions implemented in Matlab.

Directed Flow Inhaler: The primary objective of this project is to design and model a controllable inhaler for adaptable medicine delivery. Inhalers are useful and cost effective methods of medicine delivery for a range of respiratory diseases; however, in many cases, the disease affects only one lung. Inhaler delivered medication in its current state delivers equal amounts of medication to both lungs, necessitating higher doses the body must be exposed to in order for one lung to receive the proper amount of treatment. Therefore, students were instructed to design an inhaler that delivers medicine such that one lung receives the majority of the medicine. For a successful design, students must understand how air particles travel through the bronchioles based on starting positions in the mouth and then be able to target that specific area of the mouth. The design must also be robust enough to deliver a sufficient number of medicine cycles to remain cost effective to the user. 
One group of students selected this project. Their design consists of a standard inhaler mouthpiece that contains a nozzle with both a stiff and flexible part. When actuated, a shape memory alloy (SMA) wire deflects the nozzle tip to a certain angle to deposit the medication. The team first uses ANSYS Fluent, a commercial CFD tool, to determine a location in the mouth that allows more medication to be delivered to a certain lung. This information is then used in a structural model developed in Abaqus to determine the stresses the nozzle experiences during deflection and medicine dispersion.

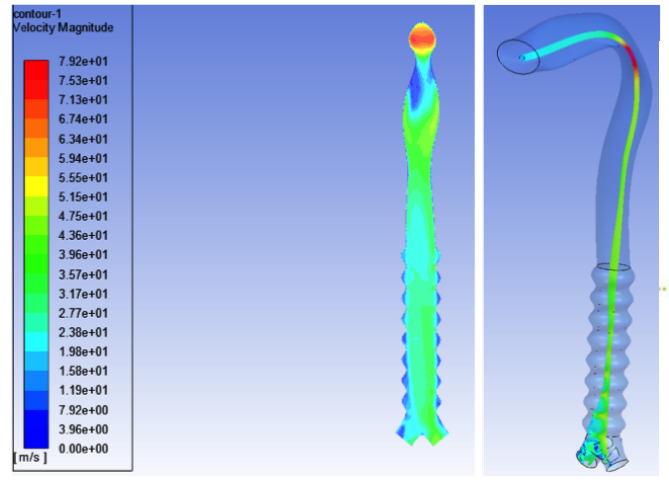

(a) Optimal solution for Fluent model of medicine in airway (targeting right lung).

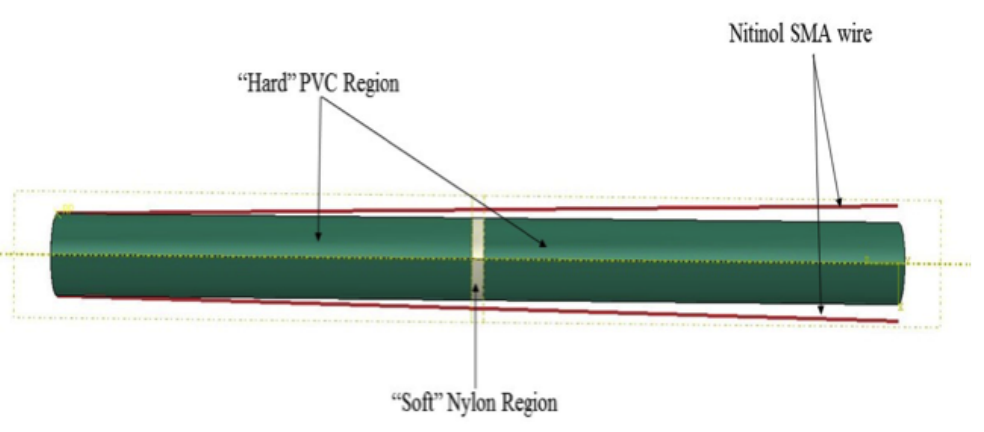

(b) Schematic of nozzle from structural model.

Figure 3: Inhaler team fluid model and nozzle description.

Stent Deployment: The objective of this project is to design an optimized stent that is structurally capable of producing the required radial force to expand an occluded artery that also minimally interferes with blood flow when fully installed. Stents are medical devices used to internally open and support arteries that are experiencing reduced blood flow due to blockages. Some key issues result, however, when the stent is expanded too much upon install, causing undue strain on the arterial wall, or when it is expanded too little, leading to stent migration away from the desired area. A successful design must mitigate both these risks while still performing the primary function of a stent, and therefore must maximize radial force while minimizing arterial strain and maintaining a profile that minimally interacts with the flow through the stent.

One group chose this project as well. The group's Abaqus structural model focuses on one strut of the stent patterned radially to make a row, which is then patterned vertically to construct the entire stent. Parameters that change curvature, width, height, and thickness of the strut are varied during the optimization, and maximum radial force produced from the stent as well as strain in the arterial wall are produced from this model. The geometry is simultaneously put through a fluid model designed in SolidWorks FlowSim, where change in velocity of the fluid and change in pressure of the fluid across the stent are obtained. Best designs from the optimization are those where radial force is maximized, arterial strain is minimized, and change in fluid velocity and pressure is minimized. 


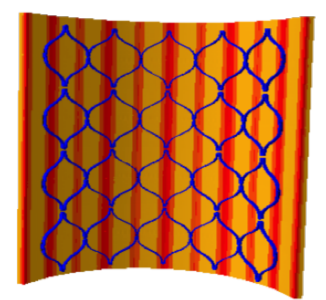

(a) Abaqus model of patterned stent (stripe shows mirror plane).

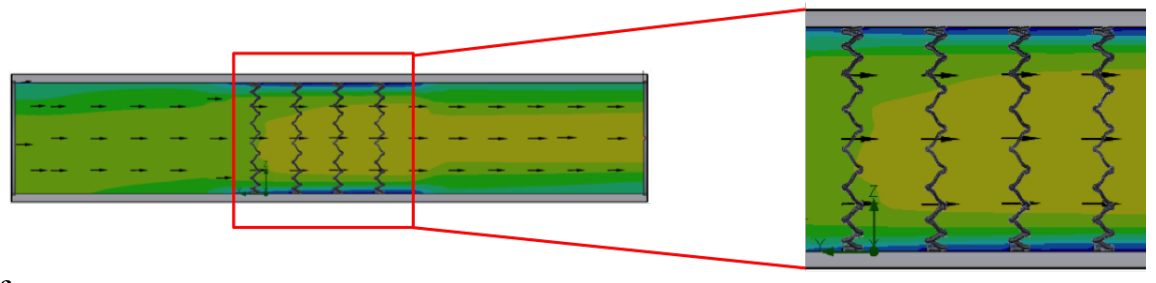

(b) FlowSim model of fluid flow through stent.

Figure 4: Stent team fluid and structures models.

Tourniquet: This project's goal is to design and model a tourniquet and its impact on the brachial artery (upper arm) for an emergency medicine situation. In the case of traumatic injuries where significant amounts of blood may be lost, a tourniquet may be applied above the injured area to stop blood flow to that area and increase the likelihood of survival of the injured person while they are transported to a secondary care facility. However, some current tourniquet designs contain key flaws and can either fail to fully stop blood flow or tighten too significantly and introduce additional tissue damage and lacerations. A successful design must deform the brachial artery sufficiently to prevent flow, while ensuring the stress on outer tissue is minimized.

Two groups chose this project option, and each took different approaches both in design and modeling. One group modified a traditional windlass design to include a shaped insert designed to specifically target the brachial artery. This group's structural model, developed in Abaqus, simulates the compression of the brachial artery as a result of the tourniquet. Input variables to the structural model include total pressure applied, insert shape, insert location as an angle, tourniquet band thickness, and insert material properties. The resulting shape of the artery from the results of the structural model is then used to calculate the blood pressure drop over the tourniquet application area through the group's fluid model. Navier-Stokes conservation of momentum is used to calculate volumetric flow rate based on initial dimensions. The Carreau-Garambuto model, a method of determining change in viscosity due to shear rate, is then used to calculate non-Newtonian effects based on the altered artery geometry, and that result is then used to calculate total pressure drop due to viscous effects and Bernoulli area variation. This result is compared with the arterial occlusion pressure found using Graham's formula, a method of determining how tight a tourniquet needs to be to occlude blood flow, to determine the efficacy of the design.

The other group chose a pressure cuff-based design for their tourniquet; a band encircled the arm and a vessel filled with pressurized gas applied pressure to a targeted area. The group's Abaqus-based structural model varies the area (length and width) that the gas could enter as well as the band thickness and amount of gas allowed to enter the vessel. Post-compression artery geometry is outputted from this model and used in a Bernoulli pipe-flow model to determine occlusion percentage. The structural model also determined the maximum stress experienced by the skin, which is compared with a crack propagation critical stress for skin to determine if a laceration occurs. 


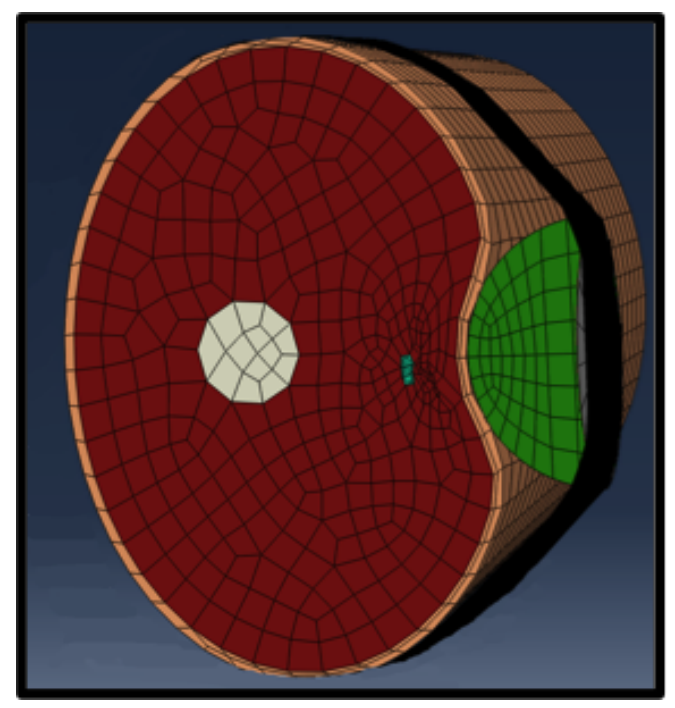

(a) Abaqus model of targeted insert (colorized to show material properties).

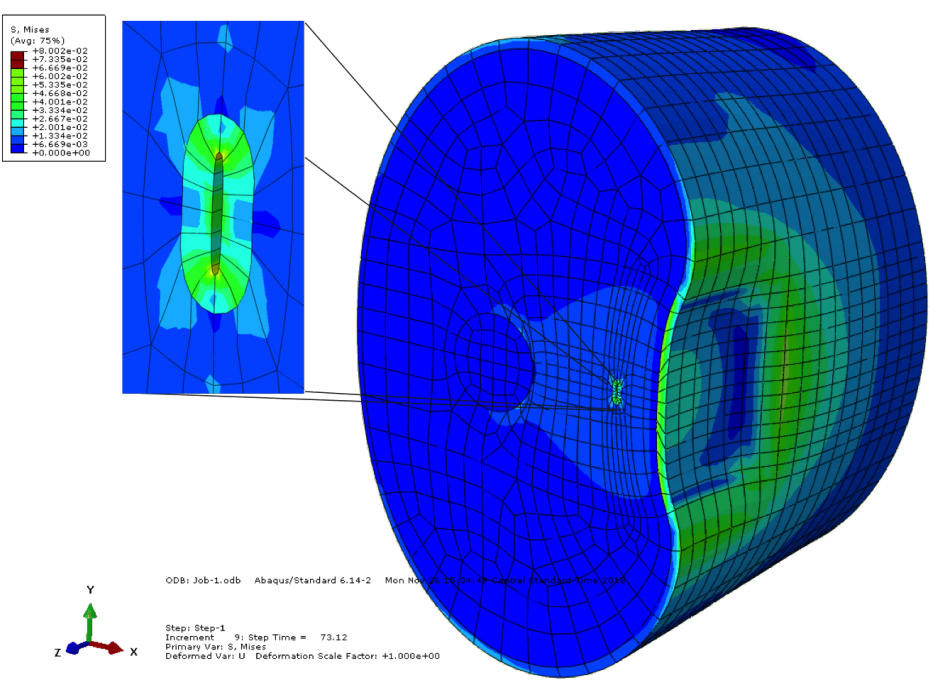

(b) Abaqus model of pressure vessel occluding artery.

Figure 5: Tourniquet teams's structural models.

\section{Results}

\subsection{Survey Outcomes}

Students were surveyed during the first week of class and again one month after the class had ended and asked "To what extent do you think that aerospace engineering deals with the following applications?". There were trends such that after completing the course, students reported believing that aerospace deals with (1) providing energy for the future, (2) restoring and improving urban infrastructure, (3) improving the environment, (4) improving healthcare, (5) improving education through personalized learning, and (6) securing personal and organizational information more so than when they began the course (tables 3 and 4 ). However, significant differences between time points were not observed given our small sample size. Tables 1 and 2 are broken up by gender to show the comparison of men and women's interest in topics within aerospace, while tables 3 and 4 reflect the knowledge all students of both genders felt they had before and after the class. 
Table 1: Women's reported interest in application of aerospace engineering at Time 1. Note: N=3

\begin{tabular}{|l|l|l|l|l|l|l|l|}
\hline & $\begin{array}{l}\text { Provide en- } \\
\text { ergy for the } \\
\text { future }\end{array}$ & $\begin{array}{l}\text { Restore and } \\
\text { improve ur- } \\
\text { ban infras- } \\
\text { tructure }\end{array}$ & $\begin{array}{l}\text { Improve } \\
\text { the envi- } \\
\text { ronment } \\
\text { (e.g., clean } \\
\text { water and } \\
\text { clean air) }\end{array}$ & $\begin{array}{l}\text { Improve } \\
\text { healthcare } \\
\text { technology }\end{array}$ & $\begin{array}{l}\text { Improve } \\
\text { education } \\
\text { through } \\
\text { person- } \\
\text { alized } \\
\text { learning }\end{array}$ & $\begin{array}{l}\text { Secure } \\
\text { personal } \\
\text { and orga- } \\
\text { nizational } \\
\text { information }\end{array}$ & $\begin{array}{l}\text { Explore } \\
\text { space }\end{array}$ \\
\hline Mean & 3.67 & 2.67 & 4 & 3.33 & 3 & 2.67 & 4.67 \\
\hline SD & 0.58 & 0.58 & 1 & 0.58 & 0 & 0.58 & 0.58 \\
\hline
\end{tabular}

Table 2: Men's reported interest in application of aerospace engineering at Time 1. Note: N=13

\begin{tabular}{|l|l|l|l|l|l|l|l|}
\hline & $\begin{array}{l}\text { Provide en- } \\
\text { ergy for the } \\
\text { future }\end{array}$ & $\begin{array}{l}\text { Restore and } \\
\text { improve ur- } \\
\text { ban infras- } \\
\text { tructure }\end{array}$ & $\begin{array}{l}\text { Improve } \\
\text { the envi- } \\
\text { ronment } \\
\text { (e.g., clean } \\
\text { water and } \\
\text { clean air) }\end{array}$ & $\begin{array}{l}\text { Improve } \\
\text { healthcare } \\
\text { technology }\end{array}$ & $\begin{array}{l}\text { Improve } \\
\text { education } \\
\text { through } \\
\text { person- } \\
\text { alized } \\
\text { learning }\end{array}$ & $\begin{array}{l}\text { Secure } \\
\text { personal } \\
\text { and orga- } \\
\text { nizational } \\
\text { information }\end{array}$ & $\begin{array}{l}\text { Explore } \\
\text { space }\end{array}$ \\
\hline Mean & 3.92 & 3.23 & 3.23 & 2.85 & 3.69 & 3 & 4.46 \\
\hline SD & 0.76 & 1.01 & 1.3 & 1.21 & 1.32 & 1 & 0.88 \\
\hline
\end{tabular}

Table 3: Students' Knowledge of Aerospace Applications at Time 1. Note: N=16

\begin{tabular}{|l|l|l|l|l|l|l|l|}
\hline & $\begin{array}{l}\text { Provide en- } \\
\text { ergy for the } \\
\text { future }\end{array}$ & $\begin{array}{l}\text { Restore and } \\
\text { improve ur- } \\
\text { ban infras- } \\
\text { tructure }\end{array}$ & $\begin{array}{l}\text { Improve } \\
\text { the envi- } \\
\text { ronment } \\
\text { (e.g., clean } \\
\text { water and } \\
\text { clean air) }\end{array}$ & $\begin{array}{l}\text { Improve } \\
\text { healthcare } \\
\text { technology }\end{array}$ & $\begin{array}{l}\text { Improve } \\
\text { education } \\
\text { through } \\
\text { person- } \\
\text { alized } \\
\text { learning }\end{array}$ & $\begin{array}{l}\text { Secure } \\
\text { personal } \\
\text { and orga- } \\
\text { nizational } \\
\text { information }\end{array}$ & $\begin{array}{l}\text { Explore } \\
\text { space }\end{array}$ \\
\hline Mean & 3.56 & 2.94 & 3 & 2.44 & 2.69 & 2.50 & 5 \\
\hline SD & 1.03 & 1.24 & 1.26 & 1.09 & 1.25 & 1.26 & 0 \\
\hline
\end{tabular}

Table 4: Students' Knowledge of Aerospace Applications at Time 2. Note: N=6

\begin{tabular}{|l|l|l|l|l|l|l|l|}
\hline & $\begin{array}{l}\text { Provide en- } \\
\text { ergy for the } \\
\text { future }\end{array}$ & $\begin{array}{l}\text { Restore and } \\
\text { improve ur- } \\
\text { ban infras- } \\
\text { tructure }\end{array}$ & $\begin{array}{l}\text { Improve } \\
\text { the envi- } \\
\text { ronment } \\
\text { (e.g., clean } \\
\text { water and } \\
\text { clean air) }\end{array}$ & $\begin{array}{l}\text { Improve } \\
\text { healthcare } \\
\text { technology }\end{array}$ & $\begin{array}{l}\text { Improve } \\
\text { education } \\
\text { through } \\
\text { person- } \\
\text { alized } \\
\text { learning }\end{array}$ & $\begin{array}{l}\text { Secure } \\
\text { personal } \\
\text { and orga- } \\
\text { nizational } \\
\text { information }\end{array}$ & $\begin{array}{l}\text { Explore } \\
\text { space }\end{array}$ \\
\hline Mean & 4 & 3 & 3.67 & 3.33 & 3.67 & 3.17 & 4.17 \\
\hline SD & 0.71 & 0.63 & 0.52 & 0.52 & 1.37 & 1.17 & .75 \\
\hline
\end{tabular}




\subsection{Interviews}

Towards the end of this course, all 15 present students were interviewed about how this course impacted them and their perceptions of aerospace engineering. When asked what they enjoyed most about the class, many students reported that it broadened their perceptions of the potential applications of aerospace engineering $(N=5)$. For example, one student wrote that after completing this course, they realized they could apply their skill set to "scan peoples mouths or look at blood flow". Students were also asked in what ways this course changed their perceptions of the field as a whole, to which the majority $(N=8)$ responded that it expanded their breadth of knowledge of aerospace applications and, for some, their knowledge of potential career paths (e.g.,"It showed that with my degree I can do more than I thought"). One student explained that this class helped them realize when complex aerospace concepts are broken down into "fundamental parts," one can "apply [them] anywhere" because this type of approach involves "looking at [a problem] more abstractly". When asked if this class gave them the confidence to pursue career areas they would not have in the past, a large majority $(N=11)$ responded in the affirmative. For example, one student stated that they have "started applying to medical places now", while another student stated that they have sought out and received "interviews with oil companies". Finally, students were asked how their interest level in aerospace engineering would have changed had these ideas and concepts been introduced earlier (e.g., during recruitment, as a first year engineer, etc.). The responses to this question were split, with some $(N=7)$ indicating that this class would have been better suited for more junior engineering students and others stating that the class is ideal for any year of education $(N=5)$. Those who wished the class had been offered earlier stated that this field would be perceived as less of a "pinhole" if students were aware of the range of "different career choices" early on. In summary, students who completed this course reported greater knowledge of and confidence in pursuing non-traditional applications of aerospace engineering.

\section{Conclusions}

Overall, students reported a high satisfaction rate with this class. In their interviews, students reported feeling more prepared for a wider variety of career choices as well as more confident in their choice of aerospace engineering as a major. Many students expressed an interest in seeing a version of this course implemented earlier in the curriculum, around sophomore year for example, as a way to encourage students to view aerospace more openly. The work completed for the major projects in this class was of high quality and value, and the skills learned and applied in this course have directly benefitted these senior students in their job application process.

\subsection{Lessons Learned}

Designed as the first step in a multi-year project, this class was key in determining areas where improvement is needed for future iterations. A key takeaway is more instruction is needed in the fluid analysis software. Though students developed mathematical models or used simpler 
programs like FlowSim, instruction in ANSYS Fluent or another commercial package would be most beneficial to students at this level. In addition, although the biomedical focus was useful for this first implementation, future versions of this course should integrate projects spanning other disciplines to appeal to an even broader range of students.

\subsection{Future Work}

The foundations this class built in this "unconventional" area of aerospace will be iterated upon and introduced in new ways. In the next year, this class will be transitioned from a senior design elective to a senior design capstone, a two-semester course where students will build prototypes of their designs and test them appropriately. Additionally, a similar class will be modified and adapted for implementation at a sophomore level, as giving students insights into non-traditional applications earlier would aid in department-level retention and student engagement.

\section{Acknowledgments}

The authors would like to thank the members of the AERO 489 class for their hard work and contributions to the images included in this paper. Funding for this work is provided by NSF Project 1730693.

\section{References}

[1] L.F. Fitzgerald and N.E. Betz. Issues in the vocational psychology of women. Handbook of Vocational Psychology, 1:83-159.

[2] C. Hill, C. Corbett, and A. St Rose. Why so few? Women in science, technology, engineering, and mathematics. American Association of University Women, Washington, DC.

[3] National Academy of Sciences. Rising above the gathering storm: Energizing and employing america for a brighter economic future. The National Academy Press, Washington, DC.

[4] S. Olson and D.G. Riordan. Engage to excel: Producing one million additional college graduates with degrees. in science, technology, engineering, and mathematics. Report to the president. Executive Office of the President.

[5] President's council of advisors on science technology (pcast). (2012). report to the president, engage to excel: producing one million additional college graduates with degrees in science, technology, engineering, and mathematics. In of the President, President's Council of Advisors on Science and Technology. Executive Office, Washington, D.C, .

[6] President's council on jobs and competitiveness announces industry leaders' commitment to double engineering internships in 2012, . URL https://www.whitehouse.gov/the-pressoffice/2011/08/31/ president-s-council-jobs-and-competitiveness-announces-industry-leaders. 
[7] Texas Workforce Commission United States. 2014 texas workforce commission annual report. URL http://www.twc.state.tx.us/files/news/annual-report-2014-twc.pdf.

[8] Western Interstate Commission for Higher Education (WICHE). (2012). Strategies for success: Promising ideas in adult college completion. Lane, Boulder, $\mathrm{CO}$, .

[9] U.S.Census Bureau. Most children younger than age 1 are minorities, census bureau. URL https://www.census.gov/newsroom/releases/archives/population/cb12-90.html. 